through a step -by step process, funding support, and ongoing opportunities within the network.

Conclusion We hope that this model can be shared to enable others to access it and help iinform their systems development. Whilst the model is not exhaustive and requires further research,it represents a first step,with lessons learnt from paediatricians with actual experience of creating such networks. Hub and spoke service provision better meets the needs of all children no matter where they live in the world.

\section{G279(P) RSV PREVALENCE IN INFANTS ADMITTED WITH BRONCHIOLITIS ACROSS CENTRAL KENYA; A PROSPECTIVE STUDY DURING GLOBAL LINKS PLACEMENT}

'J Le Geyt, ${ }^{2} \mathrm{~S}$ Hauck, ${ }^{3} \mathrm{M}$ Lee, ${ }^{4} \mathrm{~J}$ Mackintosh, ${ }^{5} \mathrm{~J}$ Slater, ${ }^{6} \mathrm{D}$ Razon, ${ }^{7} \mathrm{~B}$ Williams. ${ }^{7}$ Paediatric Emergency Department, Royal Alexandra Hospital, Brighton, UK; ${ }^{2}$ Epidemiologist, Nanyuki District Hospital, Nanyuki, Kenya; ${ }^{3}$ Paediatrics, Northwick Park Hospital, London, UK; ${ }^{4}$ Paediatrics, John Raddliffe Hospital, Oxford, UK; ${ }^{5}$ Paediatrics, Yorkshire Deanery, Yorkshire, UK; ${ }^{6}$ Paediatrics, Royal Manchester Children's Hospital, Manchester, UK; ${ }^{7}$ Paediatric Infectious Diseases, Northwick Park Hospital, London, UK

\subsection{6/archdischild-2018-rcpch.271}

Background Acute respiratory infections (ARI) continue to be a leading cause of under-five mortality in the developing world. Distinguishing between bacterial and viral causes can be challenging, and although the majority are likely to be viral, most are treated as bacterial pneumonia. In Kenya, the prevalence of Respiratory Syncytial Virus (RSV) in previous, single-centre studies have varied greatly.

Aims To determine the prevalence of RSV infection in children admitted with ARI to five hospitals in Kenya, and to analyse if there were any significant associations between RSV infection and clinical signs.

Methods A prospective cross-sectional prevalence study was conducted in five different district hospitals across central and highland Kenya from April to June 2015. Lead paediatricians were Global Links volunteers (RCPCH). Children admitted who fitted the WHO criteria for bronchiolitis had bedside RSV immunochromatography testing, and data collected about their demographics, symtpoms and signs.

Results 234 participants were enrolled across the five hospitals. The overall RSV positive rate was $8.1 \%$, although this varied between the sites. The average age of RSV positive cases was 3.9 months and RSV negative 9.2 months. Difficulty in feeding was the only clinical sign significantly associated with an RSV positive result.

Conclusion This is the first published study to look at the RSV prevalence rate in children admitted with ARIs in these areas across central and highland Kenya. The RSV rate of $8.1 \%$ is much lower than that previously reported in other parts of Kenya. Much further work is needed to better understand the viral aetiology of paediatric ARIs across the different areas of Kenya to be able to make evidenced based decisions for future public health programs and clinical guidelines.

\section{G280(P) EFFECTIVENESS OF PLASTIC BAGS VERSUS INCUBATOR IN PRETERM AND LOW BIRTH WEIGHT NEONATES}

W Mazher. Department of Paediatrics, Civil Hospital Karachi, Karachi, Pakistan
Aims Use of Plastic bags to prevent heat loss can be a feasible and cheaper option. Utilisation of plastic bags or wraps has been shown to prevent heat loss among very low birth weight and very preterm infants. Our aim is to compare the effectiveness of plastic bags in comparison to incubator in preterm and low birth weight neonates.

Methods We conducted a Randomised control trialat the Paediatrics Unit, Civil Hospital, Karachi for six months from 18th May 2016 To 17th November 2016. Non-probability consecutive sampling was used for the study. Newborns with gestational age $<37$ weeks and birth weight between 1000 and less than 2500 grams of either gender were included. Neonates with congenital malformation, skin blisters, open neural tube defects, abdominal wall defects and congenital heart defects were excluded. Total 100 newborns were randomly allocated into Interventional group and in control group. In control group initial axillary temperature was obtained. Repeat was obtained at 1 hour. In intervention group the infants remained in the plastic bag for at least 1 hour after birth, axillary temperature was noted and if the temperature found to be $>36.5^{\circ} \mathrm{C}$, effectiveness was positive. Descriptive statistics were calculated. Stratification was done. Chi-square test was applied post stratification and p-value $\leq 0.05$ was considered as significant.

Results In group-A (Plastic Bag Group), mean neonatal temperature at admission was $32.88^{\circ} \mathrm{C} \pm 1.27^{\circ} \mathrm{C}$ and in group- $\mathrm{B}$ (Incubator group), it was $32.05^{\circ} \mathrm{C} \pm 1.28^{\circ} \mathrm{C}$. In group-A, mean neonatal temperature after 1 hour was $36.97^{\circ} \mathrm{C} \pm 0.70^{\circ} \mathrm{C}$ and in group-B it was $36.82^{\circ} \mathrm{C} \pm 0.76^{\circ} \mathrm{C}$. In group-A effectiveness was $52.5 \%$ and in group-B it was $47.5 \%$.

Conclusion Our study found out that thermal protection of the newborn can relatively easily be achieved by wrapping the infant with plastic bad after birth. Use of plastic bags was found more effective than incubators.

\section{G281(P) PERSPECTIVE OF SYRIAN ADOLESCENT REFUGEES ON PROBLEMS LIVING IN ZAATARI REFUGEE CAMP}

Y Fardous, H Bedford, P Winyard, V Palit. UCL Great Ormond Street Institute of Child Health, University College London, London, UK

\subsection{6/archdischild-2018-rcpch.273}

Aims The main aim of the study is to explore Syrian adolescent refugees' perspectives on problems related to living in Zaatari camp, the largest refugee camp in the Middle East. The second aim is to discuss the possibility of these problems affecting these refugees' mental health and psychosocial wellbeing. Since only a few studies have explored Syrian adolescents' experience of living in a refugee camp, this research hopes to fill an important gap by interviewing a group of vulnerable people whom are often neglected.

Methodology Qualitative methods were used. Seventeen Syrian adolescent refugees living in Zaatari camp, aged 12-17 years, were interviewed using Tool 10 from the World Health Organisation 'Mental Health and Psychosocial Needs and Resources: Toolkit for Humanitarian Settings'.

Findings Current living conditions were key triggers of emotional problems in female participants and behavioural problems in male participants. All participants expressed that seeking various forms of distraction and social engagement were their main coping mechanisms (table 1). 
Abstract G281(P) Table 1 Problems reported

\begin{tabular}{|c|c|c|}
\hline Interview question & Themes & Sub-themes \\
\hline \multirow[t]{9}{*}{ General problems produced by living in a refugee camp } & \multirow[t]{2}{*}{ Education } & Classrooms \\
\hline & & School life and location \\
\hline & \multirow[t]{5}{*}{ Camp setting } & Lack of electricity \\
\hline & & Lack of water \\
\hline & & Enclosed camp \\
\hline & & Financial problems \\
\hline & & Long waiting hours at the hospital \\
\hline & \multirow[t]{2}{*}{ Daily routine } & Boredom \\
\hline & & Social life in the camp \\
\hline \multirow[t]{8}{*}{ Most importnat mental health and psychosocial problems } & \multirow[t]{2}{*}{ Child protection issues } & Child marriage \\
\hline & & Child labour \\
\hline & \multirow[t]{4}{*}{ Ongoing worries } & Security \\
\hline & & Violence and bullying \\
\hline & & Domestic abuse \\
\hline & & Fears about the future \\
\hline & \multirow[t]{2}{*}{ Feelings of sadness } & Missing Syria \\
\hline & & Bereavement over people left behind \\
\hline
\end{tabular}

Conclusion Participants suffer a variety of psychosocial problems, mostly related to camp structure. However, this does not necessarily imply that they suffer from a mental disorder. With few validated assessment tools and great psychosocial distress, it is imperative to validate more tools to screen for mental disorders. Strengthening existing coping mechanisms such as social cohesion can help buffer many aspects of their distress. Finally, future research to substantiate this study's findings is required.

\section{G282(P) CAUSES OF MORTALITY IN A SIERRA LEONEAN DISTRICT HOSPITAL NEONATAL UNIT}

S Kirolos, J Sesay. Neonatal Unit, Kabala Government Hospital, Kabala, Koinadugu District, Sierra Leone

\subsection{6/archdischild-2018-rcpch.274}

Introduction Neonates are one of the most vulnerable groups of patients worldwide, and this is even more so in lowresource settings. In 2015, neonatal mortality in Sierra Leone was estimated at 35/1,000 live births. Although impossible to determine exactly, it is thought that $45 \%$ of under-five mortality worldwide occurs in the neonatal group. Basic neonatal care can make a significant difference in reducing morbidity and mortality.

Aim To ascertain the main causes of mortality in a Sierra Leonean district hospital neonatal unit.

Method Neonatal admissions over a four-month period from 1 st March 2017 to 30th June 2017 were retrospectively analysed. Data collected included demographics, main diagnosis, treatment and final outcome.

Results Over the study period there were 97 admissions to the neonatal unit. $20.6 \%$ had a birth weight less than $2000 \mathrm{~g}$. Overall mortality was $21.6 \%$. Given the lack of reliable diagnostic investigations, the main causes of death were ascertained based on history and clinical assessment. Of the neonates that did not survive, $47.6 \%$ had hypoxic ischaemic encephalopathy, defined as the need for resuscitation at birth and abnormal neurological examination thereafter. Prematiruty accounted for $23.8 \%$ of deaths, and this was determined by known gestation or clinical appearance of the neonate at birth when exact gestation was not known. The median birth weight of the premature neonates who died was $1005 \mathrm{~g}$, with more than half of them also having severe respiratory distress. Presumed sepsis accounted for 19\% of deaths.

Conclusion This is a report of the main causes of neonatal mortality in a neonatal unit in a Sierra Leonean district hospital. At the time of data collection, this unit was supported by an international non-government organisation and the average in-hospital birth rate was 90 live births per month. Almost half of deaths were secondary to hypoxic ischaemic encephalopathy, with the remainder being related to prematurity and its complications or presumed sepsis. Interventions aimed at reducing this burden of mortality include national neonatal resuscitation training, emphasis on prompt delivery of broad spectrum antibiotics for neonates with signs of early onset sepsis and basic care of the preterm infant, including kangaroo mother care.

\section{G283(P) IMPLEMENTATION OF EMERGENCY TRIAGE ASSESSMENT AND TREATMENT (ETAT+) IN A SIERRA LEONEAN DISTRICT HOSPITAL}

S Kirolos, I Sesay. Paediatric Department, Kabala Government Hospital, Kabala, Sierra Leone

\subsection{6/archdischild-2018-rcpch.275}

Introduction Paediatric under-five mortality in Sierra Leone is one of the highest worldwide at 114/1000 live births in 2016 . A history of civil war and viral haemorrhagic fever outbreak has impeded growth and development of the country's health system. With a lack of resources and very few paediatric trained staff, children's health care in Sierra Leone is greatly disadvantaged. The ETAT+protocols have been developed to improve emergency care of paediatric patients in low-resource settings.

Aim To ascertain the impact of implementing national ETAT + protocols on the quality of care and mortality in malaria admissions in a Sierra Leonean district hospital.

Methods Data on all paediatric malaria admissions were collected over a four-month period between 01/03/17 and 30/06/ 